\title{
Making Every Moment Count
}

\author{
Directed by Leora Kuttner, Coproduced by the National Film Board of Canada and \\ Still Water Pictures, Running Time $\mathbf{4 0}$ Minutes
}

\author{
Javier R. Kane \\ University of Texas Health Science Center, Supportive and Palliative Care Program, CHRISTUS Santa Rosa \\ Children's Hospital, San Antonio, Tex., USA
}

The death of a child is always a tragic, painful and emotionally charged event. Children and their parents suffer tremendously throughout the illness and health care providers involved in palliative care often find themselves dealing with very complex issues, as they struggle to satisfy their patient and family's multiple physical, emotional and spiritual needs. Making Every Moment Count, a 40-min documentary directed by Leora Kuttner and coproduced by the National Film Board of Canada and Still Water Pictures, brings the world of these children, their families and care providers to a larger audience.

Over the last few years, we have witnessed a surge of interest in pediatric palliative medicine as a field dedicated to promote family-oriented medical care aimed at attending to the suffering of seriously ill children and helping them achieve the best quality of life possible, regardless of the curative intent of therapy. Making Every Moment Count is consistent with this vision of comprehensive and compassionate care. While the stories lean towards the latter stages of the illness trajectory, in combination with the commentaries of the parents and children, the documentary adequately represents the full range of pediatric illnesses, age groups and disease stages, from active treatment of disease to end-of-life care.

Reprinted with permission from the Journal of Palliative Medicine, vol. 8, No. 4, 2005 (@ Mary Ann Liebert Inc.). (c) 2007 S. Karger AG, Basel

1011-7571/07/0167-0048\$23.50/0

Fax +41613061234

E-Mail karger@karger.ch

www.karger.com
Accessible online at: www.karger.com/mpp
The stories and images presented in this video are simple yet powerful and filled with pertinent and valuable teaching moments. Rachel, a wise and peaceful teenager with cystic fibrosis suffering from complications after lung transplant, appears visibly short of breath to talk about her own death and share her story of hope. Rachel and her father, John, remind us that communication between children and their parents is important and that adolescents may and sometimes should participate in the process of making decisions regarding their own care. Her story also brings out the relational nature of this process and how healing may result even in the most painful of circumstances.

Mikaela, an insightful and articulate school-aged girl suffering from a brain tumor, expresses her feeling of 'being stuck in a donut', as she creatively describes the concept of futility in the continued use of treatments with curative intent in the presence of advancing cancer. Mikaela's story shows how difficult it is to make decisions and find a sense of order in the midst of chaos. As a master teacher, Mikaela gently leads the viewer to a greater understanding of the importance of meaningful relationships in the lives of those who suffer from a serious illness. Mikaela's sister, Mariesa, makes it clear that the siblings of children with a serious illness also need the support of their families and health care providers as they may struggle with difficult emotions and experience feelings of isolation. 
The video tells the story of Garrett, a young boy who suffers from a progressively disabling illness, and his mother, Ginger. Ginger's anguish is visibly agonizing as she shares the painful and often unbearable realities of her son's incurable illness. She offers a powerful example of how excruciatingly difficult it is for the parents of seriously ill children to make the right decisions and to provide the best possible care for their children. Through the support of a compassionate group of interdisciplinary health care professionals, she is empowered with knowledge, skills and resources that allow her to feel competent in the care of her child and cope with the challenges that concern her.

The story of Merrily, Neil, and their baby son Aaron who died at home soon after being discharged from the hospital is another compelling example. The images in this story capture Aaron's progressive decline. With the help of the health care team, Aaron's parents allowed him to die at home as a loved member of his family. The images of a health care professional in the background providing manual bag ventilation to this baby at home while his parents and his 3-year-old sister participate in his care are captivating. At one point, Aaron is seen in his mother's arms with Merrily and Neil sobbing over him, but the documentary also shows Merrily and Neil as bereaved parents reflecting on their experiences. Listening to their story full of personal meanings is enriching.

Finally, the documentary shows a nurse visiting a Chinese girl at home who is suffering from a complex medical condition. The caregiver is full of compassion, empathizes with the child's mother, and communicates with her through an interpreter. The images depict this child at home as a member of a functional family. The story brings out the relevance of providing culturally sensitive care and the wisdom of listening to families and providing care that is consistent with their personal beliefs and values.
Expert commentaries from palliative care professionals strengthen the stories and help the viewer to recognize important palliative care concepts. The families' experiences are accurately described as a 'cascade of sorrows'. Experts note how families must deal with uncertainty and a roller coaster of often confusing emotions. They emphasize the need to support them during challenging times and in the process of making extraordinarily difficult decisions. The video correctly notes how important it is to communicate with children about their experiences and how this may happen through play, imagery, and symbolism. The documentary also explains the variety of settings in which palliative care may be delivered including the hospital, the inpatient hospice or home. Finally, experts point out some of the challenges for health care providers and help the viewer understand that suffering and death are not medical problems to be solved but rather mysteries to be experienced in the presence of healing relationships.

This documentary is a powerful testament of the suffering of seriously ill children, the anguish that their parents experience, and the absolute need to make expert palliative care available to them. It is a compelling and insightful presentation that offers a glimpse into the richness of human experiences that we encounter in the care of children suffering from life-threatening and terminal illnesses. It gives a sense of hope in the healing power of meaningful relationships and the caring attitudes of compassionate health care providers. The fact that important issues such as pain and symptom management, bereavement care or care coordination are not addressed in a significant way does not detract from its value as a tool potentially useful to change the viewer's attitude toward children's suffering, death and pediatric palliative care. The value of this documentary as an educational tool for medical students, residents and other allied health care disciplines should be explored. 